\title{
El Maranon (Anacardium occidentale) en Florida ${ }^{1}$
}

\author{
John McLaughlin, Carlos Balerdi y Jonathan Crane ${ }^{2}$
}

Nombre Científico: Anacardium occidentale

Sinónimos: Acajuba occidentalis, Cassuvium

pomiferum

Otros Nombres: Merey, Cajuil, Cashew apple (Inglés), Caju (Portugés), Acaju (Francés)

Familia: Anacardiaceae

Otras Plantas en la Misma Familia: mango (Mangifera indica), Brazilian pepper (Schinus terebinthifolius), ciruelas (Spondias spp.) y poison Ivy (Toxicodendron radicans)

Origen: Noreste del Brasil

Distribución: El marañón está distribuido en todas las regiones tropicales del planeta y plantaciones comerciales existen en muchas áreas que incluyen el este de Africa, el sudeste asiático, la India y Australia, siendo la India y Brasil los principales productores. Debido a que este árbol requiere un clima tropical y no resiste las heladas, su distribución en los Estados Unidos está limitada al extremo sur de Florida y a Hawaii. No existe una producción comercial significativa en este país, pero el marañón se encuentra en colecciones botánicas y en algunos patios.

Historia: En el siglo XVI, los exploradores portugueses llevaron primero el marañón a la India (Goa) y más tarde a Mozambique (Africa). A partir de estas áreas, el cultivo del marañón se extendió a otras regiones del este africano y a Angola y también al sudeste asiático y norte de Australia. Es probable que los exploradores españoles fueron responsables de la distribución de esta planta hacia Centro América y la Cuenca Caribeña. El marañón fué importado por primera vez a los Estados Unidos, desde la India, a inicios del siglo XX. Aunque la nuez del marañón es ahora el producto más importante del árbol, inicialmente el "fruto" fué el producto que atrajo la mayor atención comercial. En el área caribeña, América del Sur, Centro América y este del Africa, el marañón se cultiva exclusivamente para el consumo local del "fruto."

1. Este documento, HS1041, es uno de una serie de publicaciones del Departamento de Horticultural Sciences, Servicio de Extensión Cooperativa de la Florida, Instituto de Alimentos y Ciencias Agrícolas, Universidad de la Florida. (UF/IUFAS). Fecha de primera publicación: 2004. Repasado November 12, 2005. Por favor visite nuestro sitio web EDIS en 〈http://edis.ifas.ufl.edu〉.

2. Drs. J. McLaughin y C. Balerdi trabajan en el Servicio de Extensión del condado Miami-Dade, Homestead, FL; Dr. J. Crane trabaja en Tropical Research and Education Center, Homestead, FL.

Traducido al Español por Rubén Regalado y C. F. Balerdi, Servicio de Extensión del condado Miami-Dade.

El Instituto de Alimentos y Ciencias Agrícolas es un empleador que opera bajo Acción Afirmativa y provee Oportunidades Igualitarias, autorizado a proveer investigación, información educativa y otros servicios, únicamente a los individuos e instituciones que operan sin discriminación alguna con relación al credo, color, religión, edad, incapacidad, sexo, orientación sexual, estado civil, nacionalidad, opinion política o afiliaciones. Para más información sobre como obtener otras publicaciones de extensión, comuníquese con la oficina de Servicio de Extensión de su condado. Servicio de Extensión de la Florida / Instituto de Alimentos y Ciencias Agrícolas / Universidad de la Florida / Larry Arrington, Decano. 


\section{Descripción}

Arbol

Cuando el marañón crece en condiciones ideales es un árbol atractivo, de tronco erecto que alcanza los 45 pies y con una corteza lisa y de color carmelita. Posee un follaje perenne que desarrolla una copa densa y simétrica. La ramificación del tronco comienza muy cerca del suelo y las ramas que se ponen en contacto con el mismo pueden enraizarse. Usualmente donde las condiciones no son óptimas, el árbol no alcanza una altura mayor de 30-35 pies y puede crecer en forma desordenada sin desarrollar un tronco definido. En estos casos aunque el valor ornamental de los árboles disminuye, el colorido vistoso de los frutos es aún una característica atractiva.

Donde las condiciones del suelo lo permiten (e.g., suelos arenosos profundos), el árbol desarrolla una raíz pivotante profunda. Los suelos calcáreos de Miami-Dade impiden un desarrollo sustancial de la raíz pivotante. El marañón produce rápidamente un sistema extenso de raices laterales que se extiende más alla del borde limitado por la copa.

\section{Hojas}

Son de color verde, simples, alternas y con un peciolo corto. Tienen una longitud de 6-7 pulgadas y su extremo es redondeado o a veces con una muesca. Su textura es lisa, dura, maleable y muestra venas prominentes.

\section{Inflorescencia}

Las flores del marañón se disponen en panículos terminales que poseen una longitud de 4-8 pulgadas. Los panículos están formados predominantemente por flores masculinas y algunas flores hermafroditas-no existen flores femeninas. Las flores, de olor agradable, son pequeñas ( 0.4 pulgadas), tienen cinco pétalos de color verde amarillento que se tornan rosados y se enroscan a medida que la flor se abre completamente. Las flores son receptivas al polen sólo durante un día. El estigma se activa inmediatamente pero la liberación del polen ocurre más tarde, por lo que existe la posibilidad de fertilización cruzada.

\section{Fruto}

El fruto verdadero (la nuez) tiene forma arriñonada y está constituido por una corteza gruesa (formada por un exocarpo grueso, un endocarpo duro, ambos separados por un mesocarpo resinoso) que rodea al embrión. El fruto es verde al inicio pero se torna carmelita grisozo paulatinamente. Cuando el fruto se acerca a la madurez, el receptáculo se hincha y desarrolla una pulpa jugosa, amarilla o roja, de 2-4 pulgadas de longitud y que tiene forma de pera. Este pseudofruto es conocido como la "manzana" del marañón.

Se debe tener mucho cuidado cuando se manipulan las nueces ya que la corteza contiene un aceite cáustico y venenoso que puede causar una dermatitis severa en individuos suceptibles. Note que el marañón se encuentra en la misma familia que el Brazilian Pepper y el Poison Ivy, ambos árboles capaces de inducir reacciones alérgicas severas.

\section{Floración y Polinización}

En climas donde la estación seca y la lluviosa se alternan, las flores se producen inmediatamente después de la estación de lluvias. En los climas tropicales con lluvias durante todo el año, la floración puede ocurrir en cualquier momento. Aunque las flores hermafroditas son autofértiles, ellas no se autopolinizan. La presencia de flores perfumadas y polen pegajoso son evidencias circunstanciales del rol que juegan los insectos como agentes polinizadores. Investigaciones han demostrado que tanto el viento como una variedad de insectos actúan como agentes polinizadores pero no existe información acerca de la importancia relativa de ambos factores en las condiciones del sur de Florida.

\section{Clima y Suelos}

El marañón está bien adaptado a un clima tropical con estaciones de seca y lluvia alternas, creciendo activamente entre los $63^{\circ} \mathrm{F}$ y $100^{\circ} \mathrm{F}$. No tolera la exposición a heladas aun cuando sean breves. Una precipitación anual de 27-78 pulgadas es óptima pero los árboles sobrevivirán con 2-15 pulgadas. Más importante que la cantidad de lluvia es su distribución en el año. Es esencial que el 
período de la floración hasta la cosecha coincida con la estación seca. El marañón crece mejor en los suelos arenosos profundos pero puede desarrollarse en suelos rocosos de baja fertilidad, inadecuados para otros árboles frutales.

\section{Propagación}

El método de propagación más fácil es el uso de semillas, obtenidas al separar la nuez (fruto verdadero) de la "manzana" (pseudofruto). Las nueces se ponen en un recipiente con agua y se desechan aquellas que flotan, después de permanecer de 5-10 minutos en el mismo. Las semillas que se hunden se pueden plantar inmediatamente o secar al sol para almenacenarse. Las semillas secas deben ponerse en un recipiente hermético con virutas de madera para almacenarlas en un sitio seco y fresco. Las semillas almacenadas deben usarse en un período de 7-12 meses pero deben ponerse en remojo 24 horas antes de la siembra.

Usualmente las semillas se siembran directamente en el suelo ya que el transplante es difícil debido a la naturaleza quebradiza de las raices. Siembre 3-4 semillas y espere a que las mismas germinen en un período de 2-4 semanas. Permita que todos los arbolitos crezcan hasta que alcancen 6 pulgadas de altura, entonces seleccione la planta más vigorosa y elimine las otras dos. $\mathrm{Si}$ utiliza macetas, seleccione las del tipo biodegradables, como las de turba. Después de la germinación de las semillas, elimine las dos planticas más débiles y permita que la remanente crezca hasta alcanzar 12 pulgadas, entonces plante la maceta de turba con la plantita en el sitio seleccionado

Debido a que las plantas propagadas por semillas no replican los caracteres de la planta materna, se necesitan métodos de propagación vegetativa cuando se desean propagar cultivares con características superiores. La producción de acodos o margullos es el método preferido. Las estacas también se pueden usar para la propagación vegetativa pero es importante usar un sustrato ligero y bien aireado y proveer sombra y humedad continua. Los mejores resultados se han obtenido cuando las estacas provinieron de árboles casi adultos. Menos comunes son los injertos de yema sencilla y los laterales con yemas múltiples.

\section{Siembra y Cuidados}

Los árboles deben plantarse al sol-no toleran la sombra- en áreas que no se inunden. Ponga el árbol en el hoyo-la base del tronco debe estar a la misma altura o ligeramente superior al nivel del suelo-y rellénelo con la tierra que ud sacó del mismo. El árbol debe estar separado al menos 15 pies de cualquier otro árbol y a una distancia mayor de cualquier estructura o tubería. Generalmente no requiere mucha poda; sólo elimine las ramas inferiores hasta 1-2 pies del suelo y las ramas muertas.

\section{Fertilización}

El marañón responde bien a la fertilización pero no existen recomendaciones específicas para el condado Miami-Dade. Las recomendaciones siguientes están basadas en experiencias obtenidas con árboles frutales relacionados y cultivados en Miami-Dade. Use un fertilizante para árboles frutales (8-3-9) o un fertilizante de liberación lenta para palmas (8-4-12) con un $2-4 \%$ de magnesio y otros micronutrientes. El fertilizante especial para palmas es adecuado para la mayoría de los árboles y arbustos tropicales en el condado Miami-Dade. Durante el primer año, aplique $4 \mathrm{oz}$ de fertilizante cada 2 meses. En el segundo año aumente gradualmente la cantidad aplicada hasta alcanzar de 8 oz a $1 \mathrm{lb}$ por aplicación en el tercer año. Para contrarrestar las deficiencias de micronutrientes, especialmente de manganeso y cinc, deben aplicarse soluciones foliares 4-6 veces por año entre abril y septiembre. La deficiencia de hierro produce síntomas severos y puede ser corregida con un baño de quelato de hierro al suelo, apropiado para suelos con $\mathrm{pH}$ superior a 7.5, con una tasa de 0.5-2.0 oz/árbol/año y durante el período de junio a septiembre.

Anualmente, los árboles adultos requieren un total de 15-20 lbs de fertilizante, dividido en tres aplicaciones: una al comenzar la floración, otra cuando los frutos estén creciendo y una final en agosto. Las aplicaciones foliares se realizan de la 
misma forma descrita anteriormente. Incremente la cantidad de quelato de hierro a 3-4 oz/árbol/año.

\section{Riego}

El marañón es nativo de una región con clima seco por lo que no prospera cuando la lluvia o el riego son excesivos. El árbol, sin embargo, se beneficiará de agua suplementaria cuando está floreciendo o produciendo frutos. Restrinja el riego, aun durante estos períodos, a una vez por semana si no ha llovido. En otras épocas del año no necesita riego.

\section{Plagas y Enfermedades}

No existe información específica acerca de problemas causados por plagas en el condado Miami-Dade. En zonas tropicales donde existe gran experiencia en el cultivo extensivo del marañón, las plagas más importantes incluyen a: insectos barrenadores (estadios larvales de escarabajos y polillas), insectos que destruyen flores u hojas (escarabajos, orugas, trips o piojillos y míridos) y aquellos que atacan a los frutos (chinches, escarabajos y orugas).

Varios hongos patógenos se han reportado como causantes de manchas en las hojas, muerte regresiva de ramitas o daño a flores y frutos. Al igual que en el mango, la antracnosis es el problema potencial más serio en el condado Miami-Dade, especialmente durante la floración y producción de frutos. Para su prevención, aplique un fungicida que contenga cobre. Comience las aplicaciones cuando los panículos tengan 1 pulgada de longitud y continue semanalmente hasta 3-4 semanas después de que los frutos estén cuajados. En este momento la frecuencia de aplicaciones puede reducirse, exceptuando los períodos de mucha humedad. El hongo polvoroso o mildiú (Oidium) provoca la destrucción de las flores del mango y se puede esperar que cause problemas similares en el marañón. Use aplicaciones de azufre líquido durante la floración, intercaladas con las de cobre para minimizar el daño de este hongo.

\section{Control de Malezas}

Mantenga un anillo de 4-6 pies libre de malezas o césped alrededor del tronco. Una capa de cobertura vegetal de 2-4 pulgadas de espesor ayudará a suprimir el crecimiento de malezas, pero asegúrese de que 6-8 pulgadas alrededor del tronco estén desnudas. No use herbicidas que contengan atrazina (para controlar malezas en el césped) en la zona de las raices del árbol.

\section{Poda}

Se requiere poca poda usualmente. Se recomienda podar las puntas de las ramas para mejorar la estructura del árbol e impedir un crecimiento desordenado. Corte 1-2 pulgadas de todas las puntas en la primavera y el verano durante los dos primeros años después de la siembra. Esta poda estimulará el crecimiento detrás de la zona donde ocurrió el despunte y promoverá el desarrollo de un árbol más compacto y con mejor estructura. La altura de los árboles debe mantenerse a 14-15 pies.

\section{Producción y Cosecha}

La humedad excesiva durante la floración y formación de frutos reduce severamente el rendimiento. En las condiciones del condado Miami-Dade es esencial adoptar un programa de fumigación similar al usado en el mango (vea Plagas y Enfermedades). Usualmente los frutos demoran de 2-3 meses para poder cosecharse. Cuando ellos maduran, caen al suelo y pueden recogerse para su procesamiento. El marañón es un fruto perecedero que se daña fácilmente y por esto se aconseja recogerlo a mano antes de que caiga al suelo, sí el árbol se sembró con el objetivo de consumir el fruto y no la nuez.

El rendimiento de un árbol depende del número de flores hermafroditas que el mismo produce. Es importante recordar que como la mayoría de las flores producidas son masculinas el rendimiento no estará en relación directa con el nivel de floración. En los paises donde se cultiva el marañón comercialmente se han desarrollado cultivares que incrementan el número de flores hermafroditas. $\mathrm{Al}$ igual que en otros árboles frutales como el mango y 
el aguacate es común la caida de algunos frutos. Un árbol adulto es capaz de producir alrededor de 50-75 lbs de frutos ("manzana" y nuez).

\section{Procesamiento}

No se aconseja el consumo de nueces producidas en patios. Su corteza contiene un aceite de color carmelita rojizo que es muy urticante. El mismo está compuesto por varios lípidos fenólicos que actuan como un agente vesicante poderoso, causando ampollas extensas en la piel. La extración de la "almendra" (endospermo) de la nuez requiere precauciones especiales. Primero se tuestan las nueces para eliminar los aceites antes de descotezarla. Esto no se debe intentar en los hogares y mucho menos en espacios cerrados ya que el aceite es volátil y puede causar problemas respiratorios severos. También es importante impedir que las "almendras" se contaminen con el aceite cuando se descortezan las nueces.

La "manzana" se usa fresca para consumir su jugo o preservado en forma de al mibar o pasta. El fruto fresco es muy astringente debido a su alto contenido en taninos y tiene un sabor más agradable si se procesa para eliminar el sabor amargo. Esto se puede realizar cocinándolos a presión durante 10-15 minutos o hirviéndolos en agua con sal durante 15 minutos. Después se presionan para eliminar el exceso de humedad y se cocinan en al mibar de caña de azúcar por dos horas. Finalmente, se secan al sol o se ponen en un deshidratador. El marañón también se conserva enlatado en al mibar, se usa para preparar chutney y pasta de frutas y debido a su alto contenido en pectina, produce jaleas fácilmente. El jugo también pueder ser consumido, para lo cual después de la extracción se cuela y se le añade gelatina ( $1 / 4$ oz por 3 tazas de jugo) y se agita constantemente durante 15 minutos. Los taninos en el jugo se combinan con la gelatina y forman un precipitado, que puede ser eliminado fácilmente cuando el jugo se cuela a través de un filtro de muselina. Se le puede añadir azúcar al gusto. El jugo se fermenta fácilmente y se usa en varios paises para preparar vinos y licores destilados (e.g., Brasil, Cuba, Guatemala, Africa occidental, India, Sri Lanka y Las Filipinas). Tenga cuidado cuando manipule el jugo pués mancha las ropas permanentemente. 